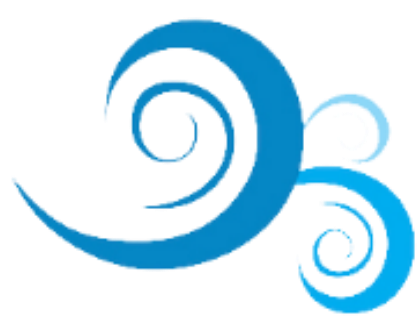

\title{
AS RELAÇÕES INTERNACIONAIS E SEUS EPISTEMICÍDIOS ${ }^{1}$
}

\author{
MARTA FERNÁNDEZ \\ Professora Adjunta do Instituto de Relações Internacionais da PUC-Rio
}

\begin{abstract}
RESUMO: O artigo argumenta que a disciplina das Relações Internacionais é cúmplice do projeto colonial e, nesse sentido, vem participando do processo histórico de epistemicídio. Tanto perspectivas realistas como liberais das Relações Internacionais reificam uma "história única", embora narrada como universal. A partir dos mitos mobilizados pela disciplina a exemplo do "estado de natureza" e do "contrato social" pretende-se iluminar sua trajetória eurocêntrica, chamando a atenção para as violências e exclusões constitutivas da mesma. O artigo, inspirado em perspectivas decoloniais, conclui enfatizando a importância da abertura da disciplina para outros saberes e cosmologias tradicionalmente silenciados e inferiorizados que podem vir a contribuir para desestabilizar suas fundações racistas.
\end{abstract}

PALAVRAS-CHAVE: epistemicídio; colonialidade; estado de natureza.

\section{INTERNATIONAL RELATIONS AND ITS EPISTEMICIDES}

ABSTRACT: The article argues that the discipline of International Relations is complicit in the colonial project and, in this sense, takes part in the historical process of epistemicide. Both realist and liberal perspectives in International Relations reify a "single story" narrated though as universal. Through the myths mobilized by the discipline, such as the myths of the "state of nature" and the "social contract", the text aims at putting light on its Eurocentric trajectory, calling attention to its constitutive forms of violence and exclusions. The article, inspired by decolonial perspectives, concludes by emphasizing the importance of opening of the discipline to other knowledges and cosmologies, that have been traditionally silenced and inferiorized, and that can contribute to destabilize the discipline's racist foundations

KEYWORDS: epistemicide; coloniality; state of nature

\section{Introdução}

O artigo visa chamar a atenção para a cumplicidade das Relações Internacionais com o projeto colonial focando nos epistemicídios silenciados e produzidos pela disciplina. O termo epistemicídio foi cunhado pelo sociólogo português Boaventura de Sousa Santos para se referir a um processo, levado a

\footnotetext{
1 Esse artigo foi inspirado na minha participação na mesa redonda de Teoria das Relações Internacionais da ABRI (Associação Brasileira de Relações Internacionais) em 2018.
} 
cabo nos últimos cinco séculos, de supressão de conhecimentos locais, cosmovisões e saberes outros presentes nas "sociedades e sociabilidades coloniais" (SANTOS, 2018:36) Por meio de tal processo, "uma imensa riqueza de experiências cognitivas foi perdida" (SANTOS, 2010: 39-40). Contra o epistemicídio praticado pelo colonialismo e pela ciência moderna, o artigo pretende oferecer uma contribuição para o processo de decolonização das Relações Internacionais, a partir do entendimento de que um primeiro passo para decolonizar a disciplina é revelar seu compromisso com uma única visão de mundo, que exclui do seu campo visual uma miríade de conhecimentos historicamente subjugados, saberes não hegemônicos, antirracistas, anti-patriarcais e anti-capitalistas.

Diversos autores pós-coloniais e decoloniais ${ }^{2}$ devotaram atenção para o impacto da colonização sobre as mentes dos colonizados e para os epistemicídios resultantes desse processo. Na palestra "Os Perigos de uma História Única", a escritora nigeriana Chimamanda Adichie nos conta, por exemplo, que, quando criança, só lia livros infantis britânicos e norte-americanos e que, quando começou a escrever, passou a reproduzir as estórias que lia, onde os personagens eram brancos, de olhos azuis, comiam maças, brincavam na neve e falavam muito sobre o tempo, ressaltando como era bom que o sol tivesse aparecido. A dissonância entre aquele mundo e o seu, contudo, não era uma questão para a escritora naqueles dias da sua infância. O poder daquelas estórias consistia justamente na habilidade de contar sobre subjetividades e experiências de vida distantes da realidade da autora como se fossem estórias definitivas e únicas dela própria, ainda que ela morasse na Nigéria, onde não havia neve, comia-se manga e as pessoas só falavam do tempo quando necessário.

Em "Pele Negra, Máscaras Brancas", Frantz Fanon nos mostra que o primeiro sinal de que o antilhano que retornava da Europa havia se europeizado, internalizando a estória da Europa como sua, é quando dizia: "Estou muito feliz em estar com vocês. Meu Deus, como este país é quente, eu não poderia ficar aqui por muito tempo!" (FANON, 2008:49). O processo de europeização, contudo, começava na própria Martinica, onde as crianças eram escolarizadas por meio de livros de História e Literatura metropolitanas e a primeira frase que aprendiam era "Je suis

\footnotetext{
${ }^{2}$ Para uma diferenciação entre as abordagens pós-coloniais e decoloniais, ver Luciana Ballestrin: América Latina e o giro decolonial. Revista Brasileira de Ciência Política, v. 11, p. 89-117, 2013.
} 
Français" (FAUSTINO, 2018). Segundo Fanon (2008:161): "Nas Antilhas, o jovem negro que, na escola, não para de repetir 'nossos pais, os gauleses', identifica-se com o explorador, com o civilizador, com o branco que traz a verdade aos selvagens, uma verdade toda branca". Essa prática se estendia às crianças das demais colônias do Império francês, conforme nos conta Kwame Appiah (1997:28), para quem "só em sentido figurado uma criança senegalesa podia afirmar descender de Asterix".

Nessa mesma linha, o romancista queniano, Ngũgĩ wa Thiong'o, mostra no livro escrito de forma autobiográfica, "Decolonising the Mind", que as escolas no Quênia foram dominadas pela língua do colonizador e que sua formação incluía desde Oliver Twist a Bernard Shaw e Grahame Green, de tal modo que a língua e a literatura afastavam mais e mais as crianças e jovens dos seus mundos para outros mundos (THIONG, 1986). Foi nesse contexto que Thiong diz que os estudantes aprendiam a trair sua própria comunidade, uma vez que eram obrigados a delatarem seus colegas flagrados na escola ou nas cercanias falando sua língua nativa.

Ainda que o artigo focalize o processo de colonização das mentes como um dispositivo fundamental para garantir a subserviência do colonizado (ver FANON, 2008; THIONG, 1986; NANDY, 1989), entende-se que tal processo tem operado historicamente em estreita conexão com o processo genocida, de destruição de vidas (ver GROSFOGUEL, 2016). Genocídios e epistemicídios são partes constitutivas da estrutura do sistema colonial capitalista (GROSFOGUEL, 2016), um sistema que se (re)produz por meio da morte física e simbólica dos seus Outros. Para subvertê-lo, contudo, não basta atacar apenas as bases culturais, alienantes, da dominação, mas é preciso, conforme Fanon já nos advertia, investir contra as injustiças materiais, econômicas, da dominação (ver FANON, 2004; COULTHARD, 2014). A produção das injustiças cognitivas que, desde os tempos coloniais, vêm desqualificando, invisibilizando e obliterando os conhecimentos produzidos por corpos políticos outros, não-ocidentais, não-masculinos, não-heterossexuais e nãobrancos, dependeram de um movimento prévio de conquista e de extermínio conduzido na América a partir de 1492 (GROSFOGUEL, 2016). A "conquista da América" posicionou o homem branco europeu numa locação materialmente privilegiada, no suposto centro do mundo que, para se constituir e reproduzir enquanto tal, contou com uma série de invenções racistas e sexistas sobre a 
alteridade colonial. No curso desse processo, indígenas e africanos (e seus descendentes) foram relegados a uma condição de insuficiência ontológica, onde o reconhecimento, quando existente, era sempre precário e incompleto.

A partir das considerações acima sobre a conexão íntima entre a produção e distribuição dos saberes, materialidades e mortes, esse artigo buscará focar no processo da colonização do saber no campo das Relações Internacionais, chamando a atenção para seus efeitos sobre a perpetuação de uma ordem extremamente desigual e violenta. Busca-se chamar a atenção para a "história única" narrada pelas principais teorias das Relações Internacionais e para as violências e exclusões produzidas pelos seus mitos e categorias analíticas centrais. O primeiro item busca mostrar que os principais mitos e categorias mobilizados pelas Relações Internacionais, como é o caso do estado de natureza, do contrato social e do Estado moderno, participam do processo extremamente violento de desqualificação da diferença e de opressão das minorias étnico-raciais que operam fora da gramática da modernidade. No segundo item, busca-se entender, a partir de contribuições decoloniais, modernidade e colonialidade como indissociáveis, destacando a importância dos "não-seres" para constituição da "zona do ser", onde a razão e a civilização supostamente teriam lugar. Esse movimento tem como propósito revelar os limites, contradições e violências da modernidade e das disciplinas a ela atreladas, como é o caso das Relações Internacionais. Destaca-se, em seguida, a necessidade de provincializar e racializar as principais teorias das Relações Internacionais, o realismo (terceiro item) e o liberalismo (quarto item). Por meio desse movimento, busca-se problematizar o suposto universalismo dessas abordagens e, com isso, no quinto item, abrir espaço imaginativo para pensar o mundo a partir de outras cosmologias, referências e racionalidades. $O$ artigo recupera a filosofia Ubuntu como uma dessas visões alternativas de mundo, antitética ao projeto moderno/colonial.

\section{Violência em três atos: estado de natureza, contrato social e Estado moderno}


Todo estudante de Relações Internacionais tem contato, já nos primeiros anos de formação universitária, com aquelas que são consideradas as principais teorias das Relações Internacionais: o realismo e o liberalismo, bem com as variadas nuances de cada uma dessas perspectivas teóricas. Aprende-se que ambas perspectivas partem de um sistema internacional anárquico, cuja principal característica/problema é a ausência de uma autoridade centralizada tida como legítima e que tem como principal metáfora o estado de natureza. De fato, o próprio Thomas Hobbes estabeleceu uma comparação entre o estado de natureza e as relações internacionais, onde as autoridades soberanas independentes coexistiriam em constante rivalidade, como gladiadoras, "com guarnições e canhões guardando as fronteiras dos seus reinos" (HOBBES, 1988:77).

A internalização do pensamento hobbesiano nas ciências sociais e, mais particularmente, na área das Relações Internacionais, nos condicionou a pensar que, na ausência do Estado soberano, não nos restaria outra alternativa a não ser o estado de natureza. A partir dessa imaginação dicotômica que opõe ordem/Estado à desordem/anarquia/estado de natureza, quaisquer formas de organização política, econômica e cultural alternativas ao Estado passam a ser reduzidas à categoria de não Estado e consequentemente de anarquia. O Estado soberano vestfaliano passa a ser visto pelas Relações Internacionais como a única expressão de ordem política possível e legítima, enquanto outras formas de comunidade política e de vida, que fogem às prescrições modernas, são invisibilizadas, depreciadas e/ou perseguidas.

O compromisso da ortodoxia disciplinar com o Estado-nação baliza um terreno ontológico muito limitado a partir do qual emergem as visões mainstream sobre segurança, soberania, comunidade e a metafísica da boa vida (BEIER, 2002). A obsessão das Relações Internacionais com o estado de natureza e com o impulso hobbesiano voltado para superar tal condição faz com que outras formas de vida e visões de mundo, como é o caso das tradições indígenas, sejam invalidadas como objeto de estudo legítimo da disciplina (ver BEIER, 2002).

Ainda que Hobbes nunca tenha conhecido o mundo natural sobre o qual filosofou, sua narrativa, em sua maioria baseada em relatos de viajantes (BEIER, 2002), colonizou a mente acadêmica, colocando-se como uma verdade com efeitos violentos sobre a nossa imaginação política, induzindo-nos a pensar sobre formas alternativas de comunidade política como desvios em relação ao Estado moderno. 
Outrossim, a metáfora do estado de natureza teve, segundo Beate Jahn (1999), uma importância central na estruturação da desigualdade entre as autoridades soberanas, pois foi a partir desta ideia que as sociedades foram ranqueadas como atrasadas (aquelas que se encontravam nessa condição) ou modernas (aquelas que haviam superado essa condição por meio do Estado moderno). Para Jahn (1999), os ameríndios forneceram aos europeus a evidência material do estado de natureza, já que o próprio Hobbes os situam nesta condição pré-contratual. A ideia do estado de natureza como uma condição universal a partir da qual a humanidade começou seu desenvolvimento histórico introduziu, de acordo com Jahn (1999), uma escala de tempo linear na história da humanidade. A partir daí, foi possível traçar uma linha entre dois pontos: desde o estado de natureza até o Estado moderno. Ao mesmo tempo, a concepção universalista do estado de natureza teve um efeito paradoxal uma vez que trouxe com ela uma visão de mundo baseada numa hierarquia de culturas que serviu de base para uma teoria das relações desiguais entre as comunidades políticas. Os ameríndios foram localizados em tempos históricos diferentes dos europeus a despeito do fato de que eles estavam de fato vivendo exatamente no mesmo tempo em que os seus observadores. Estas explicações, por sua vez, justificaram e naturalizaram o caminho particular do desenvolvimento da Europa (JAHN, 1999). E, este caminho, como nos mostra Walker (2006), é o do Estado moderno.

Segundo Walker (2006) a narrativa do contrato social de Hobbes confere legitimidade ao Estado ao projetar os problemas do homem para outro tempo e lugar, o estado de natureza. Essa narrativa nos mostra como os homens podem se transformar em sujeitos modernos livres e maduros (WALKER, 2006). Para tal fim, basta que eles se organizem por meio das estruturas de autoridade modernas. $\mathrm{Na}$ ausência dessas últimas, o que lhes resta é um ambiente natural não domesticado necessitando ser civilizado (Walker, 2006). Enfim, para Jahn (1999), os contatos dos europeus com os não europeus forneceram uma filosofia linear da história. Para Walker (2006) a fase final do caminho apontado por Hobbes era o Estado moderno europeu, o qual foi legitimado pelo discurso do estado de natureza.

Nesse contexto de "descobrimento", Blaney e Inayatullah (2004) consideram o teólogo dominicano Francisco de Vitória (On the American Indians, 1537) como o precursor das teorias de desenvolvimento e de modernização. Vitória se opôs à 
teoria aristotélica do escravo natural ao atribuir potencialidade de razão aos ameríndios. Se, por um lado, esse reconhecimento de uma humanidade comum entre os europeus e os ameríndios reduziu o espaço ontológico entre eles - bem delimitado na teoria de Aristóteles -, por outro lado, Vitória inseriu, no seu lugar, uma variante temporal que continuou demarcando a diferença. Os índios aparecem, portanto, como uma visão atrasada do Eu europeu, cujo potencial de razão dormente precisava ser ativado. Todavia, Vitória nos mostra que os próprios esforços dos índios para realizarem tal potencial falharam; o que significa que eles precisavam da intervenção de tutores para salvá-los de uma educação bárbara.

Neste processo, os índios saíram da condição de escravos naturais, o que pressupunha incapacidade do uso da razão, para o status de crianças ou alunos, o que demandava, por sua vez, que os europeus assumissem as funções de pais ou mestres. Fica claro, deste modo, que Vitória concebe a possibilidade de progresso e de atualização da razão dos índios desde que sujeitos à tutela dos espanhóis. Ao inserir uma distância temporal entre os europeus (professores) e os índios (crianças), Vitória temporaliza a diferença, apresentando-a como uma versão atrasada do Eu europeu. Esse modo de pensar, de acordo Blaney e Inayatullah (2004), autorizou e conferiu um ingrediente idealista à conquista imperial europeia orientada pelo "fardo do homem branco".

Kenneth Bock (1978) concorda que a conquista europeia do mundo está intimamente conectada com a formação da ideia de progresso a qual passou a ser cada vez mais assumida como um dado. Uma solução simples para o problema da diferença cultural e em concordância com o desenho cartesiano do mundo - de constância e uniformidade - bem como com a Escritura - que colocava a origem comum da humanidade - era asseverar a semelhança básica das pessoas em todas as partes do mundo e atribuir as diferenças aparentes a diferentes estágios num processo uniforme de desenvolvimento (BOCK, 1978). Como nos mostra Bock (1978), a maior parte dos acadêmicos europeus aceitou a crença segundo a qual a Europa representava o ponto de maior avanço até aquele momento enquanto as outras tribos e nações recém-descobertas representavam os primeiros passos de uma trajetória progressiva por onde a Europa já havia passado.

O segundo ato dessa narrativa teleológica em direção ao Estado é representado pelo contrato social que marca uma saída construída como 
voluntariamente acordada por indivíduos desejosos em se livrarem da situação de insegurança e brutalidade do estado de natureza e viverem sob a proteção do Estado soberano. Segundo Michael Shapiro (2008), a ideia de uma sociedade coerente e consensual subjacente à narrativa mítica do contrato social entre governantes e governados funciona como um álibi legitimador para a exclusão de grupos minoritários nas fronteiras nacionais. A existência de grupos que se encontram "fora da gramática" dos principais discursos do Estado-nação desafia o imaginário político do Estado-nação, coerente e unitário, revelando a ilusão desse constructo (Shapiro, 2008). A estória totalizante da modernidade política, dominante entre as abordagens acadêmicas, nos apresenta a narrativa de um Estado nacional não problemático representado por um contrato social baseado em escolhas relativamente livres por parte dos governados. Segundo Shapiro (2008), tal narrativa não dá conta de explicar a inserção coercitiva de corpos nesse espaço nacional. Além disso, esses corpos carregam memórias que desafiam as narrativas abstratas do Estado-nação fundadas numa lealdade unívoca, desprovida de qualquer ambiguidade (Shapiro, 2008). A aceitação de tais discursos hegemônicos ou o foco neste alinhamento nacional tende a deixar muitos sujeitos políticos nas sombras ou a torná-los invisíveis por não serem desejados na nação (SHAPIRO, 2008). Esse é caso, por exemplo, de muitas minorias étnico-raciais que têm uma relação ambígua e adversa com o Estado moderno, tido como um "alien" imposto sobre as mesmas e, enquanto tal, como um constructo que deve ser resistido para que seja possível mirar em futuros alternativos (Paolini, Darby, 1994:391).

Para Charles Mills (1997), o contrato social se sustenta a partir do mito em torno do seu aspecto voluntário, supostamente estabelecido entre indivíduos livres e iguais. Todavia, ele é, de fato, um contrato racial. Mills, assim como Shapiro, chama a atenção para o caráter coercitivo do contrato, mas vai além, ao chamar a atenção para a dimensão racial da sua violência, voltada para subjugação dos não-brancos. Mills (1997) racializa o contrato social ao argumentar que o mesmo estabelece um Estado assentado num sistema jurídico racista, onde o status de brancos e não brancos é claramente diferenciado. O Estado, portanto, opera mantendo e reproduzindo uma ordem racial estruturada a partir da posição privilegiada dos cidadãos brancos em contraposição à posição subjugada dos demais. Desse modo, a injustiça racial não é um desvio da sociedade moderna, mas a constitui. 
Finalmente, as teorias das Relações Internacionais condicionam a ontologia do político uma vez que nos disciplinam a pensar sobre a anarquia internacional como contraposta a algo mais autêntico e político, a saber, a vida dentro dos Estados, onde supostamente o progresso e a cultura podem florescer (WALKER, 1993). A partir de tal estrutura dicotômica, somos levados a pensar em todas as comunidades políticas que se desviam do Estado como desfuncionais, falidas ou frágeis. O discurso do "Estado falido" ou "frágil" não nos permite questionar a falência do modelo estatal, pois o que está em jogo por meio deste discurso é a habilidade ou não destes Estados desviantes de se ajustarem à imagem do "Estado bem-sucedido" que, por meio deste discurso, acaba tendo seu status de normalidade reafirmado e não problematizado. Questionando esse status de normalidade do Estado moderno, Vivienne Jabri (2010:44, tradução minha) coloca: "O estado modelo é, portanto, o estado europeu que, apesar do colonialismo e do holocausto, é apresentado no discurso liberal como o modelo a ser imitado". Segundo Siba Grovogui (2002), a tese do desvio africano normalmente é postulada sem problematizar o modelo de Vestfália - uma ordem internacional de Estados relativamente autônomos - e sem interrogar se tal modelo se adapta até mesmo à experiência europeia. Ou, nos termos de Mills (1997), sem interrogar a natureza racista desse Estado que opera a serviço da supremacia branca. Esse discurso, portanto, produz e reproduz o Estado como uma ambição reguladora moderna, um ideal de organização que deve ser alcançado por todos.

\section{A Filosofia da História lida através dos povos sem história}

Em 2005, Aparecida Sueli Carneiro, uma referência na luta antirracista no Brasil, defendeu no Programa de Pós-Graduação em Educação da Universidade de São Paulo a tese de doutorado intitulada "A Construção do Outro como Não-ser como fundamento do ser". O título da tese faz menção à ideia de que a negação da plena humanidade do Outro, combinada à negação da sua capacidade de produzir conhecimento e cultura e da sua capacidade para o desenvolvimento e aperfeiçoamento humano, criam as condições para a afirmação de uma razão dita universal, mas, de fato, racializada, que "hegemoniza e naturaliza a superioridade 
europeia" (CARNEIRO, 2005: 99). O Ser constrói o Não-ser, privando-o de sua plena humanidade ou de atributos que definem um Ser pleno, tais como autocontrole, cultura, desenvolvimento e progresso (CARNEIRO, 2005). Nesse processo, o Ser é indissociável do Não-ser, já que depende dessa falta para se constituir enquanto presença.

Esse processo de constituição do Ser a partir do Não-ser está presente no pensamento de uma série de autores pós-coloniais e decoloniais, como é o caso de Aimé Césaire (1972), Fanon (2004) e Edward Said (1990). Tais autores colocam em xeque a suposta autonomia da Europa bem como a ideia de que a sua formação identitária emergiu de um processo histórico meramente endógeno ao continente. Em discordância à genealogia eurocentrada que se faz presente mesmo nos trabalhos de intelectuais europeus críticos como é o caso de Michel Foucault, tais autores entendem que não há como fazer referência à história europeia sem trazer à tona uma outra história que Ihe atravessa e a constitui, a colonial. Nesse sentido, todos eles enfatizam que a Europa é uma invenção que depende da transformação do Outro, não-europeu, em bárbaro para se constituir enquanto lócus do progresso, da razão e da civilização. Nos termos dos autores decoloniais, como Walter Mignolo, a colonialidade é parte indissociável da modernidade, seu lado obscuro e necessário (MIGNOLO, 2003:30)

Retomando o que foi discutido acima, tem-se que o Não-ser é excluído da filosofia da história e do percurso mítico (desde o estado de natureza até o Estado moderno) projetado pelas principais teorias das Relações Internacionais. Como vimos, para Beate Jahn (1999), o encontro colonial criou as condições de possibilidade para uma filosofia da história liberal, baseada numa concepção linear do tempo. Os ameríndios forneceram aos europeus a prova material do estado de natureza e foram deslocados para um tempo histórico outro, diferente do dos europeus, ainda que ambos compartilhassem o mesmo tempo cronológico. Através do exame do discurso temporal antropológico, Fabian Johanes (2002) mostra que na construção do "Outro" como "selvagem", "primitivo", o tempo é usado de forma opressiva com o objetivo de temporalizar a diferença. De acordo com Johanes (2002:1): "não há conhecimento do outro que não seja também temporal, histórico, um ato político". Esta diferença temporalizada, contudo, não é entendida como permanente, mas, como veremos, no marco do discurso liberal, ela carrega consigo 
o potencial para o progresso rumo ao contrato social e a etapas mais avançadas de desenvolvimento.

Perspectivas decoloniais, contudo, nos ajudam a entender que determinados grupos humanos, os Não-seres, foram situados fora da história, fora dessa dinâmica potencialmente progressiva, por meio de um processo de desumanização que se estende até aos dias atuais. Se, por um lado, a filosofia da história liberal justificou a "missão civilizatória" europeia e o direito da Europa colonizar povos vistos como primitivos e selvagens com a promessa de conduzi-los à modernidade, por outro, 0 racismo naturalizou a inferioridade desses povos, (re)produzindo a diferença colonial e estabelecendo uma classificação racial dos seres humanos que continua em vigor hierarquizando a humanidade.

Para teóricos decoloniais como Aníbal Quijano (2005) e Grosfoguel (2016), o racismo de Estado emerge na conquista da América no século XVI. Para Grosfoguel (2016), o debate teológico sobre se índios tinham ou não alma, articulado pela monarquia espanhola no século XVI, tinha a mesma conotação do discurso científico articulado pelos Estados da Europa Ocidental no século XIX sobre a humanidade ou a animalidade do Outro a partir da biologia humana. Essa divisão racial da humanidade, por sua vez, tornou-se o princípio organizador da divisão internacional do trabalho, que resultou na acumulação capitalista em escala mundial (GROSFOGUEL, 2016). Para Quijano (2005), a raça converteu-se no primeiro critério fundamental de classificação social da população mundial. A partir de tal classificação, os negros africanos e seus descendentes foram alijados da humanidade, animalizados, passando a habitar o que Fanon denominou a "zona do não ser" (FANON, 2004). Para Achille Mbembe (2011), muito antes dos campos de concentração nazistas, o negro sequestrado da África e escravizado nas Américas foi vítima de uma tripla perda: perda de direitos sobre o seu corpo, perda de um lar e perda de estatuto político. Legitimou-se o genocídio e o epistemicídio do povo negro, que foi proibido de vivenciar suas espiritualidades e foi expropriado de seus saberes, das suas formas de pensar e sentir o mundo. Para Carneiro (2005:97), para além da desqualificação do conhecimento dos colonizados, o epistemicídio é um processo sistemático de "produção da indigência cultural" onde nega-se o acesso à educação, produz-se a inferiorização intelectual, deslegitima-se o negro como produtor de conhecimento e rebaixa-se sua capacidade cognitiva devido a obstáculos tanto 
materiais como subjetivos, relacionados ao comprometimento da sua auto-estima. 0 epistemicídio "fere de morte a racionalidade do subjugado ou a sequestra, mutila a capacidade de aprender etc." (CARNEIRO, 2005).

A potência do conceito de colonialidade reside na sua denúncia de que as relações coloniais de dominação não findaram com o término das relações coloniais (ver BALLESTRIN, 2013). À luz da colonialidade, podemos pensar como o racismo continua estruturando nossas sociedades, na medida em que todas elas são compelidas a se organizarem sob a forma de Estados soberanos. A colonialidade, com sua violência genocida e epistemicida, portanto, perpassa todos os estágios projetados pelo pensamento político ocidental: o estado de natureza, o contrato social, o Estado moderno e o sistema internacional.

\section{Neorrealismo: uma visão de mundo que se apresenta como "o" mundo.}

As teorias mainstream das Relações Internacionais desenham duas respostas diferentes para o "problema" da ausência de um Estado supranacional (anarquia internacional). Por um lado, o realismo, sobretudo o neorrealismo, expõe uma visão pessimista que atribui à anarquia ${ }^{3}$, as guerras, as inseguranças e os problemas de ação coletiva do internacional. Já para as perspectivas liberais, a anarquia não é menos problemática, mas pode ser mitigada pela presença de instituições e regimes internacionais (ver AXEROLD, KEOHANE, 1985; DOYLE, 1986).

Embora a teoria neorrealista se apresente como científica, ela expõe uma visão de mundo dentre inúmeras outras possíveis. Em nome de uma parcimônia extrema, Kenneth Waltz (1979) desenvolve uma teoria sistêmica que propõe se concentrar exclusivamente na estrutura (anárquica) do sistema internacional para explicar os padrões de comportamento das unidades (Estados) e, com isso, reprime todas as demais variáveis, a exemplo da história, da cultura e de visões de mundo das diferentes sociedades. A principal questão que Waltz se propõe a explicar é a continuidade da guerra no sistema internacional a despeito das mudanças nas

\footnotetext{
3 Para alguns realistas clássicos, a exemplo de Hans Morgenthau, as guerras derivavam essencialmente da natureza humana (MORGENTHAU, Hans. Política entre as Nações. Brasília: Editora UnB, 2002).
} 
unidades, mais especificamente: por que as guerras entre grandes potências continuam ocorrendo, apesar das diferenças políticas, econômicas e culturais entre elas? Waltz explica as regularidades do sistema internacional a partir do seu princípio organizador: a anarquia internacional. A ausência de uma autoridade supranacional que possa, do mesmo modo que o Estado soberano, resolver disputas e conferir proteção, faz com que as unidades sejam compelidas a buscarem poder a fim de sobreviverem. A busca pela sobrevivência, objetivo primeiro de toda unidade política, é fundamentalmente egoísta, posto que cada Estado conta com suas próprias capacidades para tal fim (sistema de auto-ajuda), ou no limite, com alianças, sempre provisórias e instáveis, com outros Estados.

Para Waltz, a dimensão cultural pouco importa, já que todos os Estados, independente das suas configurações domésticas, vão ser compelidos pela estrutura anárquica do sistema a ser comportarem de modo similar, buscando poder como um meio de sobrevivência. As unidades atuam, no modelo de Waltz, orientadas por cálculos autointeressados e por uma racionalidade extrema que as fazem perseguir suas respectivas independências e se posicionarem contra quaisquer Estados com pretensões hegemônicas. A visão de mundo resultante dessa empreitada intelectual disciplinadora, segundo Steve Smith $(2000,2014)$, é bastante estreita e coerente com os interesses das forças sociais dominantes, uma vez que nossa atenção é convocada a se ater às interações entre as grandes potências e aos equilíbrios produzidos a partir dessas interações. Nesse sentido, as escolhas epistemológicas feitas pelo neorrealismo têm implicações ontológicas (SMITH, 2014), uma vez que a simplificação da realidade obrada pela teoria acaba por deixar de lado, justamente, as preocupações culturais e econômicas que tanto afligem as sociedades póscoloniais e, inversamente, por priorizar as preocupações com segurança, tormento das grandes potências durante a Guerra Fria. Smith (2000) ressalta, por exemplo, que as mortes derivadas da economia, e não da política, e os atores não estatais tenderam a ser percebidos como alheios à disciplina. Cynthia Enloe resume os efeitos excludentes derivados da adoção dessa epistemologia, quando diz: "Para que uma explicação seja útil, muita dignidade humana deve ser deixada no chão da sala de corte" (1996:188, tradução minha).

Todavia, essa ontologia individualista e competitiva das Relações Internacionais, que se apresenta como um produto não intencional de uma estrutura 
anárquica inalterável que independe da agência humana, não é a realidade, nem parte dela, mas apenas uma visão, coerente as preocupações e visões de mundo dos Estados dominantes e suas elites. Waltz (1979) mostra como o sistema internacional força os Estados se socializarem, adaptarem e emularem o comportamento dos Estados mais bem-sucedidos. Thayer (2009:19) vislumbra similaridades entre o conceito de socialização de Waltz e o conceito de seleção natural de Darwin, já que o Estado é forçado a se adaptar a um ambiente externo, competitivo e hostil, enquanto os mais fracos são eliminados do centro da política internacional. Desse modo, a competição que se estabelece entre as grandes potências por autonomia elimina os competidores mais fracos, impõe padrões de comportamento militarizados em detrimento do bem-estar das sociedades nacionais, invisibiliza atores secundarizados no tabuleiro político mundial e socializa o sistema a partir de uma racionalidade individualista que não oferece margem para outras visões de mundo.

Enquanto, para Waltz, o sistema hegemônico é inviável e altamente instável, uma vez que os Estados estarão voltados, incessantemente, para a busca de poder relativo que Ihes forneça a segurança necessária em relação aos demais Estados, para Robert Gilpin (1981), também associado com o neorrealismo, a existência de um hegemônico confere estabilidade ao sistema. Autor da teoria da estabilidade hegemônica, Gilpin argumenta que é justamente o desbalanceamento de poder entre os Estados que confere estabilidade às relações internacionais e à economia mundial. Isso decorre da disposição dos Estados hegemônicos em provisionarem bens públicos internacionais, como segurança e garantia do regime econômico internacional (GILPIN, 1981).

A consolidação da teoria da estabilidade hegemônica na década de 80 responde à percepção crescente acerca do declínio da hegemonia norte-americana. Ela surge, portanto, tentando não só explicar tal declínio como remediá-lo, afinal, aqui, hegemonias são entendidas como saudáveis para o sistema. Na sua ausência, prevalece um sistema marcado pela instabilidade e pela desordem. Para Gilpin (1981), um fator decisivo para a deterioração da hegemonia norte-americana foi o crescimento do Japão, fruto do apoio militar e econômico provido pelos Estados Unidos no pós-Segunda Guerra. Sem ter de arcar com os custos da segurança internacional (que ficou sob a responsabilidade estadunidense), o Japão pôde se 
desenvolver economicamente, tornando-se um dos principais competidores dos Estados Unidos. Gilpin (1981:169) recorre a um costumeiro predicativo colonial, "ingratos", para desqualificar os supostos aliados dos Estados Unidos que teriam se aproveitado das benesses por ele distribuídas, gerando seu declínio e complicando o cumprimento dos seus deveres coletivos.

De fato, conforme John Hobson (2013) destaca, a teoria da estabilidade hegemônica, embora não reconheça sua linhagem colonial, está alinhada com a noção paternalista do dever do poder imperial (agora lido como "hegemônico") de levar a civilização e contribuir para o processo de desenvolvimento dos povos submetidos. Para Hobson (2013), a teoria articulada por Gilpin celebra a hegemonia anglo-saxônica, na medida em que, implicitamente, avança a ideia de que a Inglaterra e os Estados Unidos teriam se sacrificado, diminuindo seus poderes relativos vis-à-vis seus aliados, em nome do estabelecimento de um ordenamento internacional estável ancorado em instituições liberais. Partindo das ideias da teoria da estabilidade hegemônica desenvolvidas por Gilpin, de que as potências hegemônicas renunciam voluntariamente à busca por ganhos relativos e de que a disseminação de seus valores e instituições contribuem para a estabilização do sistema internacional, Hobson (2013) destaca o componente liberal dessa teoria que aposta na benevolência e no fardo (em alusão às noções da missão civilizatória e do fardo do homem branco de Ruyard Kipling) das potências hegemônicas. A conversão cultural dos Estados não-europeus ao livre-comércio pela hegemonia inglesa no século XIX e ao neoliberalismo pela hegemonia norte-americana através de programas de ajuste estrutural no século $X X$ se transformou em prescrições racionais, voltadas para a estabilidade e a prosperidade internacionais (HOBSON, 2013). Nesse sentido, a teoria da estabilidade hegemônica participou da (re)produção de um mundo de "histórias únicas", narradas e socializadas globalmente a partir dos valores e instituições particulares das potências anglosaxônicas.

O reconhecimento do caráter situado e provinciano das teorias mainstream das Relações Internacionais é o primeiro passo para abertura do campo para o pluriverso, para outras epistemologias e visões de mundo incomensuráveis em relação às formas violentas de lidar com a alteridade prevalecentes desde os primeiros encontros coloniais. 


\section{Racializando o Liberalismo}

Conforme já colocado, diferentemente do neorrealismo, para autores liberais, o sistema internacional anárquico pode, se não ser superado, ao menos ser reformado e disciplinado. Estas teorias se distanciam da lógica neorrealista de Waltz de auto-reprodução da anarquia internacional ao vislumbrarem a possibilidade de transformação da anarquia internacional (ver BLANEY, INAYATULLAH, 2004). A pré-condição para esse processo de domesticação do internacional, contudo, é a adoção de uma série de valores, normas e instituições, tais como a democracia, o livre-comércio, os direitos humanos, a boa governança e a cooperação via organizações e regimes internacionais. Argumentamos que tais ingredientes pensados como propulsores da paz, da justiça e da razão no internacional, contudo, não são, de modo algum, universais, mas falam desde um lugar específico, o mundo euroamericano, e refletem uma história única produzida no Ocidente, com todos os perigos que Ihes são inerentes. A partir dessa história, a diferença, identificada no Outro lido como não democrático e não liberal, é entendida como um desvio e/ou atraso em relação ao telos liberal traçado pelo mundo ocidental. O projeto liberal da paz implica, por conseguinte, num projeto paralelo de erradicação da diferença (ver Fernández, 2014).

Embora as teorias liberais, a exemplo da teoria da paz democrática (ver DOYLE, 1986) nos sejam apresentadas como teorias científicas e universalmente válidas, tal pretensão de não localização é colocada em xeque toda vez que analisamos suas omissões em relação ao enfrentamento das desigualdades distributivas, de gênero e raciais, que, desde um olhar decolonial, devem necessariamente ser combatidas para a construção de qualquer mundo que se pretenda de fato inclusivo. Uma abordagem decolonial, portanto, tem o mérito de localizar o liberalismo em contextos sociais e políticos concretos, apresentando-o como geopoliticamente condicionado e como corporificado, habitando um corpo branco e masculino.

Em outro artigo, analisei os limites do cosmopolitismo de Kant, destacando os traços racistas não nomeados da sua filosofia (FERNÁNDEZ, 2014). Para Kant, o 
modo de vida de alguns povos, como é o caso dos taitianos, não tem lugar na narrativa modernizadora europeia. A aparente falta de agressividade dos habitantes do Taiti que viveriam numa "pacífica indolência" não seria inteligível na filosofia da história kantiana, já que os taitianos não teriam as mesmas inclinações antissociais que, segundo Kant, impulsionariam o desenvolvimento racional dos indivíduos (ver FERNÁNDEZ, 2014). Nesse sentido, Kant compara os taitianos ao gado, animalizando-os, irracionalizando-os e expulsando-os da sua filosofia da história (FERNÁNDEZ, 2014). A naturalização kantiana do telos europeu é o que possibilita essa desumanização e orientalização daqueles cujos modos de existência não têm lugar na narrativa modernizadora europeia (Fernández, 2014). Para Andreas Behnke (2008), na medida em que Kant encontra algum valor moral nos selvagens, estes são construídos como semelhantes aos primeiros estágios da civilização europeia e, assim, por exemplo, os "selvagens canadenses" são percebidos como os espartanos do Novo Mundo, esperando por Licurgo para Ihes fornecer lei e forma política. Enfim, quando em contato com a diferença sob a forma dos "Outros não ocidentais", Kant não reconhece sua humanidade ou plena humanidade, produz e prescreve a morte de outras formas de vida para que o pacto narcísico (ver Bento, 2002) entre nações brancas democráticas possa prosperar.

A teoria da Paz Democrática, cujo principal expoente é Michael Doyle (1986), recupera o pensamento de Kant, invisibilizando, contudo, seus traços racistas supracitados. Inspirado pela ideia kantiana de uma Federação de Estados Livres, desenvolvida no ensaio A Paz Perpétua: Um Esboço Filosófico (1795), Doyle, demonstra, com apoio de estatísticas, a existência de uma paz separada entre democracias liberais. Estados liberais se caracterizam, segundo Doyle (1986), pela igualdade jurídica entre seus cidadãos, pela liberdade de expressão, pela existência de um governo representativo e com economia de mercado, bem como pela propriedade privada. Tais Estados tenderiam a formar uma zona de paz entre eles, enquanto continuariam se valendo da força para lidar com os Estados não liberais, entendidos como essencialmente agressivos pelo fato de não compartilharem dos mesmos constrangimentos institucionais e valores dos Estados liberais. A partir da diferenciação e hierarquização estabelecida entre Estados entre liberais e não liberais, a prescrição rumo a uma paz cada vez mais ampliada reside na transformação cultural, econômica e política desses Estados não liberais, se preciso 
por meio de práticas intervencionistas. Conforme já destacamos, contudo, a constituição do Estado e seres liberais dependem da exclusão de Outros, não liberais, isto é, dependem dessa falta para se constituir enquanto presença. Outrossim, a linha que separa os mundos e seres liberais dos não liberais também é uma linha de cor (DU BOIS,1925) que não pode ser explicada à parte da cartografia colonial.

Enquanto a teoria da paz democrática volta sua atenção para problemáticas clássicas das Relações Internacionais, como é o caso da paz e guerra entre as nações, a teoria liberal, na década de 80 , crescentemente se afasta de tais problemáticas mais gerais e se debruça sobre uma questão deveras específica: é possível haver cooperação entre Estados em condições de anarquia internacional? Essa questão, por sua vez, passa a orientar um programa de pesquisa compartilhado por liberais (institucionalistas neoliberais) e neorrealistas.

Nos anos 80 , realistas e liberais passam a compartilhar da mesma visão estreita de mundo (WAEVER, 1996), baseada na anarquia internacional, entendida como a falta de um governo comum na política mundial, e na visão dos Estados como atores atomísticos, racionais e como os principais agentes do sistema internacional. Destarte, neorrealistas e neoliberais passam a convergir quanto ao pressuposto da racionalidade dos atores, o que significa que os Estados calculam custos e benefícios dos cursos alternativos de ação a fim de maximizar suas utilidades (GRIECO, 1993). Em consonância com tal visão, Robert Keohane (1993) nos mostra que o neoliberalismo aceita o pressuposto convencional da teoria microeconômica de que os atores, incluindo o Estado, se preocupam apenas com a utilidade, ou seja, não têm nenhum interesse intrínseco no bem-estar das demais unidades do sistema.

Para além da adoção por neorrealistas e neoliberais dessa ontologia limitada, tais teóricos também parecem se aproximar epistemologicamente, uma vez que tentam confirmar a validade de seus pressupostos a partir da confrontação das teorias e dos fatos. Ao partirem tanto da mesma ontologia como da mesma epistemologia, as diferenças entre neorrealistas e neoliberais acabam se revelando bastante reduzidas, consistindo, fundamentalmente, de entendimentos divergentes sobre o papel desempenhado pelas instituições internacionais na promoção da cooperação internacional e sobre se os Estados perseguem ganhos absolutos ou 
relativos. Enquanto para os neorrealistas, a anarquia internacional estimula o conflito e a competição entre os Estados e inibe a cooperação mesmo na presença de interesses comuns, para os neoliberais, as instituições internacionais têm o potencial de mitigar os impactos negativos da anarquia sobre os Estados e promover a cooperação. Elas o fazem reduzindo as incertezas que imperam nesse ambiente anárquico e estabilizando as expectativas em relação às intenções alheias por meio da ampliação da transparência, do compartilhamento de informações, do controle do cumprimento dos compromissos assumidos, da redução dos custos das transações e da punição dos ludibriadores. Nesse ambiente transformado pelas instituições, os Estados podem se preocupar exclusivamente com seus ganhos absolutos, tornandose indiferentes aos ganhos dos demais, uma vez que cresce a confiança de que capacidades superiores não se traduzirão em ameaças (KEOHANE, 1993).

Conforme destacam Peter Wilkin e Caroline Thomas (2004), no âmbito do "debate neo-neo", todos os Estados possuem certas características independente de suas histórias, culturas ou ideologias políticas. A opção racionalista/utilitarista que informa o "debate neo-neo" negligencia, portanto, a história e, mais especificamente, a experiência de colonialismo e imperialismo experimentada pelo Terceiro Mundo, a filosofia e a sociologia, silenciando acerca do papel das ideias e das considerações éticas motivadoras das ações humanas e estatais.

\section{Reimaginando o mundo a partir de outros mundos}

Categorias africanas, como ubuntu, pan-africanismo e negritude, fornecem lentes alternativas através das quais o mundo pode ser entendido e vivenciado (THAKUR, 2015:218) ${ }^{4}$. Segundo Vineet Thakur (2015), a recuperação de tais visões

\footnotetext{
${ }^{4} \mathrm{Na}$ academia brasileira, temos assistido ao emprego de categorias tais como Quilombo de Abdias do Nascimento e Amefricanidade de Lélia Gonzalez, como formas alternativas de contribuição para as Relações Internacionais a partir das experiências das populações negras. Esse é o caso da dissertação de mestrado da aluna da UFBA, Raianna Morais Soto, intitulada "A classificação racial como organizadora da modernidade: Uma análise afrocentrada sobre a colonialidade do poder.", defendida em 2019, e da dissertação de mestrado de Ananda Vilela da Silva Oliveira, do IRI-PUCRio, intitulada "Epistemicídio e a academia de Relações Internacionais: o Projeto UNESCO e o pensamento afrodiaspórico sobre o Brasil e seu lugar no mundo", defendida em 2020. Um outro trabalho nesse sentido, com o título "Reinterpretações do Brasil: relações inter/nacionais para além da ótica eurocêntrica", foi apresentado por Andrea Gill e Thiago Braz no Encontro da ABRI (Associação Brasileira de Relações Internacionais) de 2018.
} 
africanas de mundo tem o potencial de abrir novas possibilidade de futuros alternativos em dissonância com 0 discurso mainstream das Relações Internacionais. Como vimos, a visão de mundo individualista subjacente às teorias neorrealistas e institucionalistas neoliberais nos apresenta um modelo onde os Estados agem a partir de um cálculo racional, buscando minimizar seus custos e maximizar seus benefícios, motivados exclusivamente pelos seus interesses individuais. Já de acordo com a filosofia ubuntu, um entendimento do Eu como autointeressado se revela contrário aos princípios humanos da existência comunal (THAKUR, 2015). Enquanto, no Ocidente, a forma hegemônica de lidar com a diferença tem sido através do duplo movimento descrito por Todorov que inferioriza a diferença para logo em seguida assimilá-la ou aniquilá-la (INAYATULLAH, BLANEY, 2004), prevalecendo a ideia de que minha existência depende da sua não existência, nos termos da filosofia ubuntu, a minha existência está conectada à existência de outros, prevalecendo a ideia de que eu sou porque nós somos (THAKUR, 2015). O Outro deixa de ser um competidor, um inimigo a ser vencido e eliminado (OLIVEIRA, 2016) e se torna corresponsável pela existência humana comum. A filosofia ubuntu enfatiza o altruísmo, a gentiliza, o respeito, a compaixão, a solidariedade, a política do cuidado mútuo, a conectividade e um profundo sentido de interdependência (NGCOYA, 2015; MUROVE, 2012). Na medida em que, de acordo com tal filosofia, nosso verdadeiro potencial humano só pode ser realizado em parceria com outros e que o indivíduo só existe na medida em que preenchido com interações sociais, ela aponta para insanidade da ideia de soberania individual (NGCOYA, 2015), rompendo com a noção autocentrada de sujeito (OLIVEIRA, 2016). A partir da ética ubuntu, "qualquer pessoa, inclusive o monarca, depende de outras pessoas; a partir disso, pode-se afirmar que ninguém é totalmente independente e ninguém é definitivamente inútil" (KASHINDI, 2017:11).

Se a África foi entendida nos discursos mainstream como um vazio ético, cultural e filosófico que deveria ser preenchido com os valores transmitidos via educação, religião e modernização pelo Ocidente, o ubuntu desponta como resistência, como afirmação de uma existência outra ou, como colocado por Kashindi (2017:3), como a "pedra angular da ética africana, que é biocêntrica, ou seja, centrada na vida". Murove (2012) nos mostra que esse modo de existência comunal foi perseguido e depreciado pelos colonizadores que o consideraram 
primitivo, infantil e baseado numa síndrome de dependência. Para superar essa forma atrasada de vida, os colonizadores, intoxicados pela teoria darwiniana centrada na competição e no individualismo, desarranjaram redes de parentesco e valores culturais tais como o ubuntu (MUROVE, 2012; LE GRANGE, 2011).

Se, no começo do nosso artigo, recorremos a Fanon para mostrar o epistemicídio promovido por meio dos currículos escolares na Martinica, agora recorremos a Ivy Goduka, acadêmica sul-africana citada por Le Grange (2004:39, tradução minha), para chamar a atenção para a continuidade do processo de "colonização da mente" via educação:

Embora eu seja uma estudiosa Xhosa, versada em nossas tradições, de muitas maneiras eu sou uma iniciante no engajamento com filosofias educacionais indígenas porque fui educada a partir de epistemologias eurocêntricas. Assim, viver dentro, ao lado e em face da tradição europeia torna as oportunidades para uma vida totalmente indígena, cultural, pessoal, social e espiritual uma luta diária contra a estrutura do domínio eurocêntrico.

É na luta diária contra o domínio eurocêntrico que o ubuntu ganha sentido. Para Murove (2012), a ética ubuntu se desenvolveu em contraposição às práticas desumanizantes do colonialismo e da escravidão. Nesse contexto, os colonizadores eram vistos como desprovidos de humanidade, isto é, de ubuntu, na medida em que ubuntu significava ver o outro ser humano como você mesmo e tratá-lo com respeito (MUROVE, 2012). No âmbito da ética ubuntu: "A desumanização de outros seres humanos é um impedimento para o autoconhecimento e a capacidade de desfrutar de todas as nossas potencialidades humanas" (NOGUERA, 2011/2:148). Nesse sentido, a ética do Ubuntu é a antítese da desumanização da condição colonial. A incapacidade de agir de forma humana em relação aos demais é, portanto, considerada uma falta de humanidade ou de ubuntu (MUROVE, 2012). Foi justamente a conviç̧ão de que as práticas desumanizantes e brutais do colonialismo e da escravidão eram antitéticas ao ubuntu que inflamou as revoltas contra as mesmas (MUROVE, 2012).

Nos últimos anos da década de 90 e o começo dos anos 2000, assistimos a uma ressignificação do ubuntu como "visão de mundo africana" (KASHINDI, 2017:6), em grande medida influenciada pela experiência da Comissão de Verdade e 
Reconciliação da África do Sul e pelas ideias do Arcebispo Emérito Desmond Tutu, que presidiu a Comissão. Para Tutu, apoiador da filosofia ubuntu: "Eu sou porque você é. Ser verdadeiramente auto-suficiente é ser sub-humano" (apud THAKUR, 2015:224). Em contraposição ao modelo ocidental, cujo exemplo paradigmático é a lógica punitivista de Nuremberg, a Comissão se baseava na reconciliação que, por sua vez, era fundamentada na ideia de uma humanidade comum entre agressores e vítimas (Thakur, 2015). No livro No Future without Forgiveness, Tutu propôs uma "terceira via" que se encontraria entre a "justiça vingativa", exemplificada em Nuremberg, e a "amnésia" (perda da memória) das anistias não condicionadas (KASHINDI, 2011). Conforme destaca Marcelo José Derzi Moraes (2019:5), o ubuntu "possui uma compreensão de alteridade que não se limita ao outro igual a mim (...)". Em termos de justiça, o ubuntu não procura que se faça justiça apenas à vítima, mas também ao perpetrador da violência, que se desvirtuou e negou o ubuntu. Hoje a Comissão de Verdade e Reconciliação é tida como um exemplo bemsucedido e tem servido de inspiração para outros modelos de reconstrução pósconflito.

Thakur (2015) pontua que o ubuntu não é apenas um conceito africano a ser estudado na África, mas um conceito que pode ser teorizado através do globo, tendo o mérito de criar um vocabulário alternativo, centrado na cura e na compaixão, ausente nos principais debates das Relações Internacionais. A colonização, ao mesmo tempo em que fraturou tradições africanas a exemplo do ubuntu, também as universalizou por meio do processo de desterritorialização violentamente imposto sobre povos africanos escravizados e sequestrados das suas terras rumo à Europa e suas colônias. Nesse sentido, o ubuntu se mantém vivo nas diásporas africanas e habita inúmeras sociedades pós-coloniais, a exemplo do Brasil. O ubuntu estaria presente, por exemplo, nos quilombos ${ }^{5}$ (MORAES, 2019) e nas rodas (de capoeira, de samba, de candomblé, etc.), já que as manifestações de matriz africana se organizam na forma de roda e não de filas (Oliveira, 2016), que expressam uma ideia de hierarquia. O ubuntu, nesse sentido, se constitui enquanto uma forma afrocentrada de reconfiguração das relações humanas, baseada em laços de apoio mútuo (NOGUERA, 2011/2).

\footnotetext{
${ }^{5}$ Conforme Moraes (2019), o quilombo é um lugar de harmonia com a natureza e a ancestralidade, de bem-estar, acolhimento, resistência e de um modo de vida contracolonial.
} 
Para Thakur (2015), o ubuntu lança luz sobre a natureza individualista do "internacional", oferecendo notas dissonantes, contrapontuais, à hegemonia normativa dos valores de democracia liberal e direitos humanos individuais. Conforme destaca Grosfoguel (2016:44), o Ocidente "sequestrou" as noções de democracia, de direitos humanos, de libertação da mulher, entre outras. Grosfoguel (2016:44-5), então, propõe um esforço decolonial de redefinição desses conceitos, que foram apropriados e monopolizados pela modernidade eurocêntrica como se os mesmos fossem inerentes à Europa, em múltiplas direções que reflitam a diversidade epistêmica do mundo e para além das estruturas capitalistas, patriarcais, cristãs, modernas e coloniais ${ }^{6}$.

\section{Considerações Finais}

O artigo argumentou que a disciplina das Relações Internacionais foi cúmplice do epistemicídio colonial na medida em que, a despeito da sua suposta cientificidade, foi forjada a partir de mitos e categorias analíticas que naturalizaram e continuam naturalizando o percurso trilhado pelo mundo da supremacia branca, reproduzindo suas ontologias, epistemologias e privilégios. Enquanto a noção de estado de natureza possibilitou que imaginássemos um mundo com diferentes temporalidades hierarquicamente escalonadas, a ideia do contrato social contribuiu para produzir a ideia de uma sociedade consensual enquanto de fato reproduzia as divisões raciais no âmbito do Estado moderno, resultando em genocídios e epistemicídios sistemáticos.

Tanto realistas como liberais produzem conhecimento majoritariamente a partir do mundo anglo-saxônico e teorizam com base no pensamento de poucos homens brancos, a exemplo de Hobbes e Kant, silenciando sobre outras cosmovisões e racionalidades que disputam a verdade dos discursos eurocentrados. O artigo compartilha do incômodo manifestado por Grosfoguel (2016:27) quando o

\footnotetext{
6 Autores como Ngcoya (2015) estão cientes do perigo de cooptação destas interpretações alternativas de mundo, como é o caso do ubuntu, pelos governos, para fins conservadores. $O$ autor nos mostra que na África do Sul pós-apartheid, o ubuntu foi utilizado pelo governo para fugir das suas responsabilidades sociais, transferindo-as para as comunidades com base na ética do cuidado comunitário inerente à visão de mundo ubuntu.
} 
autor indaga: "Como é que no século XXI, com tanta diversidade epistêmica existente no mundo, estejamos ancorados em estruturas epistêmicas tão provincianas camufladas de universais?". Por outro lado, vê com entusiasmo o espaço, ainda incipiente, mas cada vez maior, ocupado por abordagens póscoloniais e decoloniais nas conferências, redes e produções acadêmicas das Relações Internacionais, que têm o mérito de nos permitir enxergar outros mundos, informados por cosmologias e temporalidades alternativas que resistem, rivalizam ou mesmo são indiferentes ao olhar e expectativas coloniais.

Formas diversas de lidar com a alteridade, dos povos Dakota e Lakota (ver BEIER, 2013), dos Tupinambás (ver CASTRO, 2011), dos povos indígenas do Pacífico Negro (ver SHILLIAM, 2015), sugerem a arbitrariedade das nossas verdades mais fundamentais e têm o potencial de ativar nossa imaginação para formas outras de concepção do tempo, do espaço e da política em desacordo com as noções modernas que nos colonizaram. Tais perspectivas têm o potencial de abrir nossa imaginação para outros mundos além do ocidental, para mundos onde, segundo a inspiração zapatista, "caibam muitos mundos".

\section{Referências Bibliográficas}

ADICHIE, Chimamanda Ngozi. O Perigo da História Única, TED Global, 2009. Disponível em: https://www.ted.com/talks/chimamanda adichie the danger of a single story/trans cript?language $=$ pt Acessado em 30 de setembro de 2019.

AXEROLD, Robert, KEOHANE, Robert. Achieving Cooperation Under Anarchy: Strategies and Institutions. World Politics, v. 38, n. 1, p. 226-254, 1985.

BALLESTRIN, Luciana. América latina e o giro decolonial. Revista Brasileira de Ciência Política, n. 11, p. 89-117, 2013.

BEIER, J. Marshall. Beyond hegemonic state(ment)s of nature: indigenous knowledge and non-state possibilities in international relations. In: CHOWDHRY, G.; NAIR, S. (orgs.). Power, Postcolonialism and International Relations: Reading Race, Gender and Class. London: Routledge, 2002, p. 82-114.

BEHNKE, Andreas. Eternal Peace" as the Graveyard of the Political: A Critique of Kant's Zum Ewigen Frieden. Millennium: Journal of International Studies, v. 36, n. 3, p. 513-531, 2008. 
BENTO, Maria Aparecida Silva. Branqueamento e branquitude no Brasil. In: CARONE, Iray; BENTO, Maria Aparecida Silva (orgs.). Psicologia social do racismo - estudos sobre branquitude e branqueamento no Brasil. Petrópolis: Vozes, 2002, p. 25-58.

BOCK, Kenneth. Theories of Progress, Development, Evolution. In: BOTTOMORE, Tom; NISBERT, Robert (orgs.). A History of Sociological Analysis, New York: Basic Books, 1978, p. 39-79.

CARNEIRO, Aparecida Sueli. A Construção do Outro como não-ser como fundante do ser. Tese de doutorado apresentada ao Programa de Pós-Graduação em Educação, Universidade de São Paulo, 2005.

CASTRO, Eduardo Viveiros. The Inconstancy of the Indian Soul. Chicago: Prickly Paradigm Press, 2011.

CESAIRE, Aimé. Discourse on Colonialism. Nova York: Monthly Review Press, 1972.

COULTHARD, Glen. Red Skin, White Masks: Rejecting the Colonial Politics of Recognition. Minneapolis: Minnesota Press, 2014.

DOYLE, Michael. Liberalism and World Politics. The American Political Science Review, v. 80, n. 4, p. 1151-1169, 1986.

DU BOIS, W. E. B. Worlds of Color. Foreign Affairs, v. 3, n. 3, p. 423-44, 1925.

ENLOE, Cynthia. Margins, Silences, and Bottom Rungs: How to overcome the underestimation of Power in the Study of International Relations. In: SMITH, Steve, BOOTH, Ken; ZALEWSKY, Marysia (orgs.). International theory: Positivism and beyond. Cambridge: Cambridge University Press, 1996, p.186-202.

FANON, Frantz. Pele Negra, Máscaras Brancas, Salvador: Editora da Universidade Federal da Bahia, 2008.

. The Wretched of the Earth. New York: Grove Press, 2004.

FASOLT, Constantin. The Limits of History, Chicago: University of Chicago Press, 2004)

FAUSTINO, Deivison Mendes. Frantz Fanon: um revolucionário, particularmente negro. São Paulo: Ciclo Contínuo Editorial, 2018.

FERNÁNDEZ, Marta. O Cosmopolitismo Kantiano: Universalizando o Universalismo. Contexto Internacional, v.36 n.2, p. 417-456, 2014.

GILL, Andrea e BRAZ, Thiago. Reinterpretações do Brasil: relações inter/nacionais para além da ótica eurocêntrica. Trabalho apresentado no Encontro da ABRI (Associação Brasileira de Relações Internacionais), 2018. 
GILPIN, Robert. War and Change in World Politics, Princeton: Princeton University Press, 1981.

GRIECO, J. M. Anarchy and the Limits of Cooperation: A Realist Critique of the Newest Liberal Internationalism. In: BALDWIN, D.A. (org.). Neorealism and Neoliberalism: The Contemporary Debate. New York: Columbia University Press, 1993, p. 116-43.

GROSFOGUEL, Ramón. A estrutura do conhecimento nas universidades ocidentalizadas: racismo/sexismo epistêmico e os quatro genocídios/epistemicídios do longo século XVI. Revista Sociedade e Estado, v. 31, n. 1, p. 25-49, 2016.

GROVOGUI, Siba N. Regimes of Sovereignty: International Morality and the African Condition. European Journal of International Relations, v. 8, n. 3, p. 315-338, 2002.

HOBBES, Thomas. Leviatã. São Paulo: Abril Cultural, 1988.

HOBSON, J. M. Part 1 - Revealing the Eurocentric foundations of IPE: A critical historiography of the discipline from the classical to the modern era. Review of International Political Economy, V. 20, n. 5, p. 1024-1054, 2013.

INAYATULLAH, Naeem; BLANEY, D. L. International Relations and the Problem of Difference. New York: Routledge, 2004.

JABRI, Vivienne. War, Government, politics: a critical response to the hegemony of the liberal peace. In: RICHMOND, Oliver (org.). Palgrave advances in peacebuilding: Critical Developments and Approaches. Basingstoke: Palgrave Macmillan, 2010, p. 41-57.

JAHN, Beate. IR and the state of nature: the cultural origins of a ruling ideology. Review of International Studies, v. 25, n. 3, p. 411-34, 1999.

JOHANES, Fabian. The Time and the Other: how anthropology makes its objet. New York: Columbia University Press, 2002.

KANT, Immanuel. Para a Paz Perpétua. In: GUINSBURG, J. (org.) A Paz Perpétua. Um Projeto para Hoje. São Paulo: Perspectiva, 2004, p. 31-87.

KASHINDI, J.B. Kakosi. Ubuntu como ética africana, humanista e inclusiva. IHUideias, v. 15, n. 254, p. 3-20, 2017.

KEOHANE, R.O. Institutional theory and the realist challenge after the Cold War. In: BALDWIN, D.A. (org.). Neorealism and Neoliberalism: The Contemporary Debate. New York: Columbia University Press, 1993, p. 269-300.

LE GRANGE, Lesley. Guattari's philosophy of environment and its implications for environmental education in (post)colonial Africa. Southern African Journal of Environmental Education, v. 22, p. 35-45, 2005.

. Ubuntu, Ukama and the Healing of Nature, Self and Society. Educational Philosophy and Theory, v. 44, n. 2, p. 56-67, 2011. 
MBEMBE, Achile. Necropolítica. Santa Cruz de Tenerife: Editorial Melusina, 2011.

MIGNOLO, Walter. Historias locales/disenos globales: colonialidad, conocimientos subalternos y pensamiento fronterizo. Madrid: Akal, 2003.

MILLS, Charles W. The Racial Contract. Ithaca: Cornell University Press, 1997.

MORAES, Marcelo José Derz A filosofia ubuntu e o quilombo: a ancestralidade como questão filosófica, Revista África e Africanidades - Ano XII - n. 32, p. 1-11, 2019.

MUROVE, Munyaradzi Felix. Ubuntu. Diogenes, v. 59, n. 3-4, p. 36-47, 2012.

NANDY, Ashis. The Intimate Enemy: Loss and Recovery of Self under colonialism. New Delhi: Oxford University Press, 1989.

NOGUERA, Renato. UBUNTU COMO MODO DE EXISTIR: Elementos gerais para uma ética afroperspectivista, Revista da ABPN, v. 3, n. 6, p. 147-150, 2011/2.

NGCOYA, Myuselelo. Ubuntu: Toward an Emancipatory Cosmopolitanism? International Political Sociology, v. 9, n. 3, p. 248-262, 2015.

OLIVEIRA, Ananda Vilela da Silva. Epistemicídio e a academia de Relações Internacionais: o Projeto UNESCO e o pensamento afrodiaspórico sobre o Brasil e seu lugar no mundo. Dissertação de mestrado, Instituto de Relações Internacionais da Pontifícia Universidade Católica do Rio de Janeiro (IRI/PUC-Rio), 2020.

OLIVEIRA, Dennis. UBUNTU: uma ética africana para repensar a sociedade brasileira. A Raíz- Movimento Cidadanista, 2016, Disponível em: http://www.raiz.org.br/ubuntu-uma-etica-africana-para-repensar-sociedade-brasileira Acessado em 28 de janeiro de 2020.

PAOLINI, A; DARBY, P. Bridging International Relations and Postcolonialism. Alternatives, v. 19, n.3, p. 371-97, 1994.

QUIJANO, Aníbal. Colonialidade do poder, Eurocentrismo e América Latina. In: EDGARDO, Lander (org.). A colonialidade do saber: eurocentrismo e ciências sociais. Perspectivas latinoamericanas. Buenos Aires: CLACSO, Consejo Latinoamericano de Ciencias Sociales, 2005, p. 105-127.

SAID, Edward W. Orientalismo: O Oriente como Invenção do Ocidente. São Paulo: Companhia das Letras, 1990.

SANTOS, Boaventura de Sousa. Para Descolonizar Occidente. Mas allá del pensamento abismal. Buenos Aires: CLACSO, Consejo Latinoamericano de Ciencias Sociales, 2010.

Introducción a las Epistemologias del Sur. In: MENESES, Maria Paula; BIDASECA, Karina (orgs.). Epistemologias del Sur. Buenos Aires: CLACSO; Coimbra: Centro de Estudos Sociais- CES, 2018. 
SHAPIRO, Michael J. How does the Nation-State Work? In: EDKINS, Jenny; ZEHFUSS, Maja (orgs.). Global Politics- A New Introduction, London \& New York: Routledge, 2008, p. 220-243

SHILLIAM, Robbie. The Black Pacific: Anti-colonial struggles and oceanic connections. Londres: Bloomsbury Publishing. 2015.

SMITH, Steve. The discipline of international relations: still an American social science? British Journal of Politics and International Relations, v. 2, n. 3, p. 374-40, 2004.

Singing Our World into Existence: International Relations Theory and

September 11. International Studies Quarterly, v. 48, n. 3, p. 499 - 515, 2014.

SOTO, Raianna Morais. A classificação racial como organizadora da modernidade: Uma análise afrocentrada sobre a colonialidade do poder. Dissertação de mestrado, Programa de Pós-Graduação em Relações Internacionais da Universidade Federal da Bahia (UFBA), 2019.

THAKUR, Vineet. Africa and the Theoretical Peace in IR. International Political Sociology, v. 9, n. 3, p. 213-229, 2015.

THAYER, Bradley. Darwin and International Relations. On the evolutionary origins of war and ethnic conflict. Kentuchy: The University Press of Kentuchy, 2009.

THIONG'o, Ngugi Wa. Decolonizing the Mind. The Politics of Language in African Literature. London: James Currey, Nairobi: Heinemann Kenya, New Hampshire: Heinemann, 1986.

THOMAS, Caroline; WILKIN, Peter. Still waiting after all this years: the "Third World" on the periphery of International Relations. British Journal of Politics and International Relations, v. 6, n. 2, p. 241-258, 2004.

WALKER, R. B. J. Inside/Outside: International Relations as Political Theory. Cambridge: Cambridge University Press, 1993.

. The Double Outside of the Modern International. Ephemera. Theory \& Politics in Organization, v. 6, n. 1, p. 56-69, 2006.

WAEVER, Ole. Rise and Fall of the inter-paradigm debate. In: SMITH, S.; BOOTH, K.; ZALEWSKI, M. International Theory: Positivism and Beyond. Cambridge: Cambridge University Press, 1996, p. 149-187.

WALTZ, Kenneth. Theory of International Politics, Reading, MA: Addison Wesley, 1979. 